\title{
Somos todos negros
}

\section{Todos somos negros}

\section{We are all black}

\author{
Edilson Santos Braga \\ bragasantos.edilson@outlook.com \\ Universidade Federal de Mato Grosso, UFMT, Campus de Rondonópolis, MT \\ Welkyn Brás Pereira de Sousa \\ bwelkyn@gmail.com
}

Universidade Federal de Mato Grosso, UFMT, Campus de Rondonópolis, MT

Resumo: Este ensaio, traz uma reflexão sobre o racismo sob uma perspectiva histórica e biológica. Para tanto, buscou-se fundamentos na literatura sobre as causas do racismo no Brasil, bem como os fatores que sustentam a persistência desse sentimento em pessoas que pertencem a uma cultura e 'raça' condicionalmente derivada da mistura de povos e etnias. Diante disso, parte-se da premissa de que somos todos negros, não apenas por uma questão de miscigenação, mas por toda a configuração de nossa história em seus variados aspectos.

Palavras-chave: Racismo, Raça, Miscigenação, Brasil.

Resumen: Este ensayo trae una reflexión sobre el racismo desde una perspectiva histórica y biológica. Con este fin, buscamos fundamentos en la literatura sobre las causas del racismo en Brasil, así como los factores que respaldan la persistencia de este sentimiento en las personas que pertenecen a una cultura y 'raza' derivada condicionalmente de la mezcla de pueblos y etnias. Dado esto, se supone que todos somos negros, no solo por el mestizaje, sino por toda la configuración de nuestra historia en sus diversos aspectos.

Palabras clave: Racismo, Raza, Mestizaje, Brasil.

Abstract: This essay brings a reflection on racism from a historical and biological perspective. To this end, we sought fundamentals in the literature on the causes of racism in Brazil, as well as the factors that support the persistence of this feeling in people who belong to a culture and 'race' conditionally derived from the mixture of peoples and ethnicities. Given this, it is assumed that we are all black, not just for the sake of miscegenation, but for the whole configuration of our history in its various aspects.

Keywords: Racism, Breed, Miscegenation, Brazil.

\section{ISSO É COISA DE NEGRO}

Quem nunca viu ou já ouviu falar sobre algum caso de manifestação racista, principalmente nas redes sociais? Dentre tantos, podemos elencar aqui alguns casos de repercussão 
nacional, a exemplo do caso da jornalista Maria Júlia Coutinho, a Maju do Jornal Nacional da rede Globo de Televisão, vítima de comentários racistas na página do Jornal Nacional no Face book. Outro caso de mesma natureza é o da filha adotiva dos atores Bruno Gagliasso e Giovanna Ewbank. A criança, de 4 anos à época, foi alvo de comentários racistas a respeito da cor de sua pele e de seu cabelo, sendo chamada de 'macaca', de acordo com o portal de notícias $\mathrm{G} 1^{1}$.

Além desses, podemos lembrar o caso do jornalista William Waack, acusado de racismo após o vazamento, nas redes sociais, de um vídeo em que usou a expressão 'coisa de preto' para reclamar de buzinas nas ruas, antes da transmissão de uma cobertura no telejornal do qual era âncora. Esses são apenas alguns dos casos que repercutiram em função de seus alvos serem personalidades públicas. Quantos casos, porém, são silenciados no dia a dia, de anônimos?

"Macacos", "isso é coisa de preto" e "tinha que ser negro" são algumas das expressões que contrariam a utopia da igualdade social brasileira e revelam a face hipócrita de uma sociedade fundamentada em preconceitos, discriminação, exclusão e desigualdades sociais. Acasos essas expressões não contrariam o princípio de isonomia, especificamente nos artigos $4^{\circ}$ e $5^{\circ}$ da Constituição Federal? Além disso, considerando nossas raízes com tantas manifestações culturais Brasil afora, não seríamos todos negros? Expressões como as mencionadas anteriormente, são no mínimo repugnantes e, quando vêm carregadas de sarcasmo, evidenciam a ignorância da sociedade em relação a nossa cultura formada pela mistura de raças, em que numa perspectiva histórica, a 'raça branca' é superior e dominante no tocante as 'raças' consideradas inferiores, como o índio e o africano.

A humanidade se caracteriza, sem dúvida, por sua diversidade. Apesar disso, ainda nos deparamos com desafios constantes da difícil convivência entre os diferentes. Uma convivência marcada por exclusão e, muitas vezes, opressão, a qual delega a alguns - por uma construção histórica-social - o direito de classificar, estabelecer hierarquias e atribuir valores a outras pessoas. Como fruto dessa construção, têm-se pessoas reféns, às margens de uma sociedade demagogicamente democrática, vítimas de intolerância e de preconceito manifestados de várias maneiras como, por exemplo, a discriminação pela cor da pele ou pela etnia, que neste caso, caracteriza o racismo que, embora maquiado sob a hipocrisia utópica de uma sociedade brasileira igualitária, sempre existiu e atinge a todos cujo pecado é ter nascido com tom de pele mais escuro.

O tom de pele não define raça, nem tampouco determina se uma pessoa se sobressai a outra, portanto, categorizar pessoas por raça só tem relevância quando o objetivo é estigmatizar, pois fatos históricos comprovam a inconsistência dessa palavra.

Nas ciências modernas esse conceito não se fundamenta e de acordo com Hall (2011) trata-se apenas de uma construção política e social, ou seja, é a categoria discursiva em torno da qual se sustenta um sistema de poder socioeconômico, de exploração e exclusão. Gilroy (2007, p. 50) pondera que o "termo 'raça' conjura uma variedade peculiarmente resistente de

1 Bruno Gagliasso denuncia ofensas raciais publicadas contra a filha. Disponível em: http://g1.globo.com/jornal-nacional/ noticia/2017/11/ bruno-gagliasso-denuncia-ofensas-raciais-publicadas-contra-filha-titi.html. 
diferença natural, esteja ele articulado nas mais especializadas línguas da ciência biológica e da pseudociência, ou no idioma vernacular da cultura e do senso comum".

Ainda conforme o autor, este termo, tal como é empregado hoje, com o sentido de contrastar características conexas e comuns no que concerne ao tipo e à ascendência, é uma construção totalmente moderna que sobredetermina as relações sociais, revelando a trágica condição que une a vida de uma espécie comum.

Veremos neste ensaio, como aquilo que caracteriza 'raça' não passa de uma construção social fundamentada sobre a justificativa da diferenciação social e cultural que legitima, empregando aqui um eufemismo, a exclusão racial. É uma construção social onde se acentua uma gama de sentimentos negativos expressados em preconceitos, muitas vezes assimilados pela sociedade. O racismo, mesmo caracterizado como crime no Brasil, é um sentimento velado, expressado em várias camadas, atingindo famosos e anônimos. É um fenômeno que vai além da negritude, como Lázaro Ramos descreve em seu livro, Na minha pele. Segundo ele, o preconceito racial é algo nacional, diz respeito ao cidadão. Em suas palavras, é como se vivêssemos em um mundo que é nosso, porém não nos pertence. É um mundo que nos faz reféns de intolerâncias e ignorâncias.

Este ensaio tem por objetivo trazer reflexões sobre os fundamentos que sustentam o racismo, considerando que manifestações dessa natureza refutam o fato histórico de que nossas raízes são negras. Além disso, na negação de nossa matriz negra, há o paradoxo de uma sociedade democrática que pressupõe liberdade e igualdade de direitos para todos, mas exclui alguns. O que nos permite argumentar que a classificação e categorização das pessoas em 'raça' não se fundamenta em questões genéticas e é historicamente uma construção sociocultural de demonstração de força, onde a ideologia de que a 'raça' branca é superior a negra, está enraizada por meio da opressão de povos e costumes. Contraria-se a pluralidade da cultura brasileira e o fato incontestável de que nossas raízes, assim como a genética, nos colocam em igualdade quando se trata de raça, o que reforça a tese de que somos todos negros. Seguindo essa linha, iniciaremos a discussão sobre como se classifica o ser humano a partir da perspectiva biológica.

\section{CLASSIFICANDO PLANTAS, ANIMAIS E TAMBÉM HOMENS}

Uma das características mais remotas da humanidade é, em um processo de organização, a tendência em classificar os elementos de maneira mais homogênea possível, ou seja, é o ordenamento sistematizado que categoriza os elementos. De acordo com Magnoli (2009, p. 19), subjaz nesse princípio de classificação o pensamento de Aristóteles, segundo o qual "os itens devem ser reunidos em classes mais homogêneas possíveis; cada novo item específico deve ser agrupado à classe com a qual compartilha o maior número de atributos e; um novo item com atributos muito diferentes de todos os demais deve originar nova classe".

No campo cientifico, as classificações são fatores condicionantes na busca por respostas para os fenômenos. Vale lembrar que o princípio de classificação, caracteriza a própria 
ciência conforme Bacha (2014, p. 76): "no século XIX, a ciência ampliou sua abrangência, foram notórias as tentativas de sistematizar as diversas áreas do saber, intensificaram-se os debates em todos os ramos da ciência". Considerando que a classificação é um processo que inclui extração ou seleção de traços semelhantes para se reconhecer padrões homogêneos, no campo biológico, Magnoli (2009) sustenta que esse processo é chamado de taxonomia, onde as espécies são classificadas por critérios fisiológicos, evolutivos, anatômicos e ecológicos, contudo abre-se a ressalva: o que serve e classifica plantas e animais também serviria a homens?

Embora Magnoli (2009) afirme que as primeiras tentativas de ordenar a humanidade, classificando-a em raças datam do final do século XVII, faz-se importante elucidar que esse ordenamento no sentido de classificação, onde algumas 'raças' se sobrepõem à outras, tem raízes bem mais profundas constatadas na cultura Ocidental ligada a certas concepções quanto a natureza humana que justificaram a discriminação dos seres pautada principalmente em sua exploração. A discriminação, até o fim da Idade Média, se justificava sobre dois argumentos, um baseado na cultura e o outro na condição social (CALDAS, 2015). De acordo com o autor, enquanto os gregos se apoiavam na tese de que eram superiores aos outros povos por se considerarem mais cultos, durante o império Romano, a discriminação era sustentada pela posição social, e na Idade Média, os nobres se faziam reconhecer superiores pelos outros povos em função de alguns privilégios que lhes eram atribuídos pelos reis.

De acordo com Marques e Santos (2012), outro fato que evidencia os antecedentes e a profundidade histórica do racismo pode ser constatado no processo de colonização dos europeus contra populações nativas das américas e contra povos africanos. Contudo, de acordo com Magnoli (2009), foi no século XIX que o médico alemão Johann Friedrich Blumenbach propôs a divisão dos seres humanos em raças, nomeando-as como caucasoide, mongoloide, malaia, etiópica e americana. Além dessa classificação biológica, neste século o contexto histórico da expansão da revolução industrial e imperialismo capitalista trouxe uma carga de discriminação onde pessoas e povos agrupam-se de acordo com seus padrões. Ainda como consequência da classificação, tem-se a concepção de hierarquia das relações sociais pautada nas posições ocupadas por cada sujeito nas práticas sociais (AGUIAR, 2007). Neste caso, segundo o autor, as classificações hierárquicas geralmente são qualitativas, onde o nível mais alto está ocupado pela classe mais homogênea, logo, superior as demais.

Obstando-se a classificação feita pelo médico alemão e confrontando o que conceitualmente se atribui às características das raças (pessoas), Magnoli (2009) afirma que, na Biologia, existem dois tipos de espécies: as monotípicas e politípicas. A espécie humana é monotípica, ou seja, é constituída de apenas uma raça. Essa premissa, assumida pela genética, entende que as eventuais diferenças morfológicas entre as 'raças' não têm nenhum valor que justifique a necessidade de classificação, dado que essas diferenças são superficiais, controladas por pequenas variações genéticas decorrentes de um processo de adaptação evolutiva ao ambiente, o que nos permite dizer que os fundamentos empíricos que justificam o conceito de raça são rasos e não se sustentam. 
Sob a ótica de divisão de classes, 'raça' caracteriza-se principalmente como forma de exclusão, preconceito e desigualdade social. Para Hall (2011) o grande óbice de compreensão nesta questão está no fato do nível genético não ser diretamente identificado e, por isso, a diferença genética se sobrepõe de forma materializada e sublinhadas nos significantes corporais, como a cor da pele e as características físicas do cabelo.

Ter mais ou menos melanina não é um fator plausível capaz de determinar a que classe um indivíduo pertence, porém é um fator que o condiciona à uma posição em classe mais ou menos favorecida. Contudo, por não ter sustentação científica, fica claro que a definição de 'raça' implantada na sociedade é uma construção política e social, logo é a categoria discursiva em torno da qual se organiza um sistema de poder socioeconômico, de exploração e exclusão fundamentada sobre a justificativa da diferenciação social e cultural que legitima a exclusão racial.

No Brasil, tais fatos se evidenciam em vários contextos históricos. Conforme Guimarães (2016) em âmbito nacional, tem-se o grande marco da revolução de 1930 e posteriormente suas consequências, como o desenvolvimento capitalista brasileiro embasado na homogeneização cultural e racial. Ainda nessa seara, importante que se lembre do processo de branqueamento da população brasileira que segundo Teixeira (2017), esse processo, incentivado pelo império e apoiado por intelectuais da época se embasava nas ideias de eugenia que surgiram na Europa do século XIX. De acordo com a autora, a imigração de europeus para o Brasil incentivada pelo império, camuflava-se sob a desculpa de aqui se precisava de mão-de-obra livre, assalariada.

Contudo, percebe-se que o embranquecimento da população brasileira, incentivada e apoiada outrora, legitima à exclusão do negro em uma sociedade pós-abolicionista, nesse contexto, "o negro, marcado por uma negação existencial, e o branco, por uma supremacia narcísica e hegemônica, ambos mantêm, em grande medida, essa estrutura na contemporaneidade" (MAIA; ZAMORA, 2018, p. 282).

Por fim, em âmbito geral, Guimarães (2016) ilustra o racismo com as tragédias mundiais ocorridas por questões raciais, como por exemplo, o Holocausto, na Segunda Guerra Mundial; a segregação racial nos Estados Unidos, que perdurou no pós-guerra e o apartheid, na África do Sul.

\section{VÁRIAS MISTURAS E UM POVO, O BRASILEIRO}

Os fundamentos histórico-culturais do Brasil são marcados, desde o princípio, por desigualdades sociais, haja visto todo o seu desenvolvimento econômico e social oriundo da colonização portuguesa. Toda colonização é contrastada por submissões e dominações em que o dominador se intitula proprietário dos dominados, com direitos e poderes de decisão sobre a vida dos "mais fracos". No cenário brasileiro esse processo envolve personagens europeias, africanas, nativas do próprio Brasil, e também asiáticos.

Com tantos povos reunidos, não tem como ignorar o fenômeno da miscigenação. Moutinho (2004) descreve que a mestiçagem brasileira é fundamentada historicamente 
sobre um casal miscigenador integrado por um branco libidinoso que se aproveita das voluptuosas mulheres negras e índias, geralmente suas subordinadas. Todavia, de acordo com Reis (1961), o fato de que no primeiro século de colonização, poucas mulheres brancas emigraram para a colônia a exogamia dos lusos com mulheres nativas foi fator importante para o povoamento, ao passo que tal processo desencadeou laços afetivos.

Como se nota, o processo de miscigenação e formação do povo brasileiro, engloba vários fatores que transcendem o limite da dominação, contudo, no caso do Brasil, esse processo tem suas marcas evidentes até hoje, pois, sob o ritual de passagem da fase de criança para a fase adulta, marcada pela dizimação física do índio, das crenças e cores africanas deixadas para trás de forma hostilizante e a imponente figura europeia, formou-se um povo marcado pela mistura de cultura com traços pluralista, nos colocando em igualdade racial e cultural.

Diante disso, a cor da pele é um fator irrisório, o que nos proporciona a reflexão sobre que matizes nos definem pois, conforme Freyre (2006, p. 367), "todo brasileiro, mesmo o alvo, de cabelo louro, traz na alma, quando não na alma e no corpo [...] a sombra, ou pelo menos a pinta, do indígena e do negro". Evidencias marcadas no gingado do batuque, no samba carnavalesco, um dos maiores eventos de nossa cultura onde os povos contrastam, com efervescência, a indiferença racial.

Porém, a mesma sociedade que aprecia as cores do carnaval e o sabor da feijoada, por uma questão histórico-cultural, infelizmente ainda pende para a noção de que ter pele clara é sinônimo de superioridade, o que fundamenta as divisões de classes nos diversos contextos. Magnoli (2009) ressalva que nos contextos etnocêntricos, o termo raça foi aplicado com finalidade descritiva e com sentido associado ao tipo, linhagem e/ou ancestralidade.

A ancestralidade brasileira evidencia que somos negros porque nossas raízes são negras, partilhamos da mesma língua, dos mesmos costumes e tradições. Por mais que as evidencias históricas marquem a ignorância das pessoas em detrimento ao conceito de raça, Magnoli (2009) afirma que atualmente esse termo se aplica exclusivamente sobre as peculiaridades físicas de cada um, nos reduzindo assim, à mera classificação embasada por aspectos e/ ou características físicas.

Embora haja indicadores de classificação social como por exemplo sexo e religião, no quesito 'raça' somos todos iguais, como nos lembra a canção Olhos coloridos, resultado de uma experiência racista pela qual seu compositor, Macau, passou na década de 1970. A canção foi consagrada, na década de 1980, como um clássico da música popular brasileira na voz de Sandra de Sá: "a verdade é que você tem sangue crioulo, tem cabelo duro, sarará crioulo". Ademais, diante de todas as evidencias nas artes, modo de falar, danças e comida, podemos dizer sem hesitação que compomos um povo de cultura ímpar, marcado por um intenso processo de miscigenação, calando a interrogação sobre nossa pureza de raça bem como que raça nos define, deixando claro que temos a mistura como identidade, a mistura que origina o crioulo, o caboclo, o caipira, o sertanejo, enfim, o povo brasileiro. 


\section{O CATIVEIRO DA LIBERDADE}

O homem é por natureza um ser social que precisa interagir com o meio. É um ser flexível, cuja personalidade é moldada em consonância ao seu contexto cultural. Para Savoia e Cornick (1989, p.54), a formação da personalidade do homem é consequência "de um processo de socialização, no qual intervêm fatores inatos e adquiridos". Ressalva-se que os fatores inatos são compreendidos como aquilo que herdamos geneticamente dos nossos familiares e os fatores adquiridos provém da natureza social e cultural.

Uma das consequências da construção do homem pela sociedade é o desenvolvimento de um ser necessitado de demonstrar força, percebida sempre do ângulo dominador e dominado. Numa visão histórica, a imposição de poder do homem sobre outro é caracterizado, entre outras, por meio da força refletida em escravidão. Magnoli (2009) explana que, desde tempos imemoriais, sociedades escravizaram seres humanos como resultado de conquista, guerras ou dívida. Sob essa vertente, salienta-se que a escravidão tem um lastro marcante no desenvolvimento econômico, social e cultural das civilizações.

Na Grécia antiga, tem-se a ilustração da escravidão principalmente no tocante a restrições de cidadania. Conforme Zaparoli (2016), a civilização grega mantinha em seu cotidiano a prática da escravidão e desigualdade política, considerando que os direitos políticos eram concedidos apenas aos considerados cidadãos, especificamente àqueles nascidos em Atenas, do sexo masculino e maiores de vinte anos. Demonstração contundente de exclusão no que diz respeito a mulheres, aos de outra naturalidade e a escravos.

Perpassando as fronteiras da história, a escravidão foi se configurando e sendo demostrada nos mais variados contextos de maneira diversificada, inclusive nos dias atuais, contrariando a ideologia de 'liberdade'. A liberdade é um dos princípios de igualdade, logo, garante às pessoas o direito de ir e vir, de expressão, de religião, enfim, teoricamente garante a equidade social, embora em muitos contextos históricos os fatos afirmam outra realidade. Silei (2011) relata que mesmo com a afirmação da Constituição Norte-Americana de 1776 afirmando que "todos os homens são iguais", até meados de 1960, nos Estados Unidos, havia segregação entre brancos e negros, ou seja, viver nos Estados Unidos, em especial nos estados do Sul, para os negros era uma verdadeira luta, reprisada por preconceito, exclusão, privações, medos, homicídios entre outras questões, como por exemplo, a interdição de negros, explicitada em anúncios do tipo whites only².

Corroborando o que foi dito, de acordo com Bosi (2007) praticamente em quase todos os estados da América do Norte, onde a escravidão foi abolida, "direitos foram concedidos" aos negros, embora não pudessem exercer e desfrutar de tais direitos, como votar, por exemplo, sob risco de vida. O autor diz ainda que, oprimidos, eles podiam até se lamentar e se dirigir à magistratura, mas encontrariam só brancos entre os seus juízes. Portanto, "o que se conhece da discriminação racial ao longo dos séculos XIX e XX (linchamentos, apartheid...) só viria confirmar a reprodução dos limites internos da burguesia liberal que, chegando ao poder, sabe quem e como excluir" (BOSI, 2007, p. 360).

2 Whites only expressão do Inglês, equivalente a "apenas brancos" em Português. 
Considerando o exposto anteriormente, claramente se percebe que a escravidão apenas mudou sua configuração e seus instrumentos, continua causando danos tanto quanto nos primórdios. As leis de libertação e igualdade não são suficientes para abolir o preconceito que persiste e ainda assola a realidade de muitos.

Com o grande paradoxo da humanidade em lidar com um sistema classificatório imposto pelas próprias pessoas, ser negro até parece ser um defeito ou algo indesejável. Chrysanthème evidencia esse fato no livro Contos para criança, escrito em 1906 em um contexto brasileiro no qual o processo de branqueamento era declarado e marcado sobretudo pela eugenia. A narrativa do livro, apesar de se apresentar em contos infantis, retrata como é feita a inversão de valores e a disseminação de que ter a pele negra é um indicador de desvalorização, um defeito. Aliás, ideias que ainda são disseminadas por vários discursos, ofensas e piadinhas que massacram e distanciam cada vez mais a ideia de igualdade entre as pessoas, reforçando a ilusão da liberdade, simultâneo a discursos e teorias raciais.

Os prenúncios da abolição da escravidão no Brasil são marcados pela divisão de ideias. De um lado, os abolicionistas sob o espírito revolucionário do século XVIII, de outro os escravistas que tentavam manter esse regime justificando a importância do escravo no contexto econômico da época.

De acordo com Menezes (2009), o advento da liberdade (abolição) foi um processo lento, marcado pela mobilização social, rebeliões nas senzalas, movimentos negros tanto pacíficos quanto extremistas e, sem dúvida, muitas negociações políticas e lutas. Para Ribeiro e Piovesan (2008, p. 880), "a abolição da escravidão foi um ato isolado que não veio acompanhado de medidas de inclusão dos ex-escravos como cidadãos; tampouco contou com políticas voltadas a educação, moradia e trabalho, objetivando a inserção social dos ex-escravos". Ou seja, foi um processo falho, que marginalizou e negligenciou direitos e cidadanias a muitos cidadãos.

Almejada por todos que viviam em condições escrava, finalmente em 13 de maio de 1888, 'conquista-se' ou 'cede-se' a tão sonhada liberdade. Todavia, a ideologia de liberdade e igualdade é refutada quando se analisa os dramas vividos pelos negros, inclusive nos dias de hoje, mesmo compondo uma notável e inegável parcela da sociedade. A escravidão foi abolida, contudo o preconceito racial, enraizado na história social brasileira, deixa claro o quão ilusório foi a abolição, ou seja, os negros libertaram-se dos grilhões, troncos correntes e pelourinho, mas continuam reféns de uma sociedade absolutamente seletiva.

\section{O DESAFIO DE SER NEGRO NA ATUALIDADE}

O novo milênio é marcado por profundas mudanças tecnológicas e sociais, interligadas. De acordo com Lino (2009), nesse contexto vive-se a contemporaneidade, refletida na globalização e suas diversas dimensões, em que a novidade e o efêmero passam a ser valorizados e a fazer parte do cotidiano das pessoas. Como consequência disso, há mudanças de valores, de comportamentos, de identidade, as quais moldam novos tipos de relacionamento sociais, mais frágeis e superficiais. 
Na concepção de Camino et al. (2001), o processo de globalização cultural, apesar de intensificar as relações entre as diferentes culturas e etnias, é também um processo ambíguo, pois na medida em que cresce o respeito à diversidade de valores culturais, surgem também pressões para a manutenção das identidades e valores culturais regionais. Ou seja, na visão dos autores, a globalização traz como efeitos colaterais fenômenos de fanatismo e de discriminação contra etnias e grupos minoritários.

Considerando esses argumentos, o peso dessas consequências é maior para as consideradas 'minorias'. Este termo é muito discutido e apresentado sob diversos pontos de vista, todavia, conforme Carmo (2016), o grande ponto em comum que todas as concepções de grupos minoritários dizem respeito à estreita relação de acometimento no que tange ao poder que lhes é tirado, ao processo de dominação, à violência sofrida, à marginalização social e à uma necessidade premente de tolerância. Ou seja, pertencer, por exclusão da própria sociedade, aos grupos minoritários tem um preço, o qual acompanha a humanidade desde os primórdios. No tocante aos negros, esses são obrigados a desenvolver habilidades diárias para lidar com os desafios de uma sociedade opressora de suas próprias raízes, de uma sociedade pautada numa narrativa hegemônica, em que determinados grupos são concebidos como padrão, menosprezando e desconhecendo as particularidades de grupos que fogem à 'normalidade'.

Partindo de um conceito epistemológico para um conceito ideológico, Pestana (2016) afirma que o termo 'desafio' é uma palavra fidedigna ao representar a vida do negro na história. Segundo o autor, diariamente o negro é obrigado a enfrentar o desafio de resistir e sobreviver às piores condições de vida humana, de preservar a cultura e os costumes africanos, manter no rosto o sorriso que mascare seus dramas, lutar contra a intolerância racial, se sujeitar a qualquer tipo de emprego, ser vítima de um sistema que por estar interno nas pessoas, as vezes parece não poder ser superado.

Outro desafio, em especial das mulheres negras na atualidade, trazido por Miranda (2015) é o fato destas serem duplamente estigmatizadas, por sua condição de mulher e por sua cor, numa sociedade proeminentemente machista e racista. Um dos contrastes do grande paradoxo das políticas de inclusão, segundo a autora, está na questão da inserção da mulher negra no mercado de trabalho. Conforme Miranda (2015, p. 2) "normalmente a mulher negra é sempre preterível em relação aos seus concorrentes".

\section{AFINAL, QUEM SOMOS NÓS?}

Somos uma cultura incontestavelmente sincrética, de povos e jeitos diferente, porém limitado a hipocrisia do etnocentrismo europeu, pois todos os brasileiros, em maior ou menor grau, seja através da genética ou da cultura, temos a mesma descendência, reforçada por traços negros que nos definem. Traços que transcendem a cor da pele, tipo de cabelo ou formato labial. São traços que dão uma característica única e inconfundível à nossa cultura, deixando-a repleta de cores, ritmos e sabores. 
Deste modo, pode-se inferir que de fato, a cultura e a identidade brasileira é marcada por heranças afrodescendente. Nesse sentido, Silva (2016), entre os diversos fatores, evidencia o samba como uma identidade musical brasileira, herdado da cultura afro, e Santos (2016) ao afirmar que além dos traços físicos, da dança e da música, é na religiosidade que encontramos a presença dos africanos no nosso sangue.

Como se nota, são muitos os fatores que evidenciam o quão negro somos e negar esse fato é desconhecer a própria história, porque ser negro vai muito além da cor da pele, inclusive, a cor da pele é irrelevante, afinal, somos todos negros, como diz o inestimável Zeca Baleiro na música Canção para ninar um neguim: "preto pretinho, eu sou do gueto, branquinho de alma negra como tu [...]".

\section{REFERÊNCIAS}

AGUIAR, M.M. A construção das hierarquias sociais: classe, raça, gênero e etnicidade. Cadernos de Pesquisa do CDHIS, v.20, n. 36-37, p. 83-88, 2007.

BACHA, M.L. Comte e Peirce, sobre a classificação das ciências: o status da matemática. História da ciencia e do ensino, v 9, p., 75-91, 2014.

BOSI, A. Liberalismo versus democracia social. Estudos Avançados, v. 21, n. 59, p. 359-363, 2007.

CALDAS, L.J.P.A. O percurso histórico do racismo. In: ENID, 5, 2015. Anais eletrônico. Paraíba, 2015.

CARMO, C.M. Grupos minoritários, grupos vulneráveis e o problema da (in)tolerância: uma relação linguístico-discursiva e ideológica entre o desrespeito e a manifestação do ódio no contexto brasileiro. Rev. do Instituto de Estudos Brasileiros, n. 64, p. 201-223, ago. 2016.

FREYRE, G. Casa-grande e senzala: formação da família brasileira sob o regime da economia patriarcal. 51. ed. rev. São Paulo: Global, 2006.

GILROY, P. Entre campos: nações, cultura e o fascínio da raça. São Paulo: Annablume, 2007.

GUIMARÃES, A.S.A. Formações nacionais de classe e raça. Tempo Social, v. 28, n. 2, p. 161-182, ago. 2016.

HALL, S. Da diáspora: identidade e mediações culturais. Belo Horizonte: Ed. UFMG, 2011.

LINO, M.V.A contemporaneidade e seu impacto nas relações familiares. Revista IGT na Rede, v.6, n. 10, p. 2-13, 2009.

MAGNOLI, D. Uma gota de sangue: história do pensamento racial. São Paulo: Contexto, 2009. Disponível em: $\quad$ https://www.livrebooks.com.br/livros/uma-gota-de-sangue-historia-do-pensamento-racialdemetrio-magnoli-wmjtcgaaqbaj/baixar-ebook. Acesso em: 01 maio 2018.

MAIA, K.S.; ZAMORA, M.H.N. O Brasil e a lógica racial: do branqueamento à produção de subjetividade do racismo. Psic. Clin., v. 30, n.2, p. 265-286, 2018.

MENEZES, J.M.F. Abolição no Brasil: a construção da liberdade. Revista HISTEDBR, Campinas, n. 36, p. 83-104, dez. 2009. Disponível em: <http://www.histedbr.fe.unicamp.br/revista/edicoes/36/art07_36. pdf>. Acesso em: 26 maio 2018.

MIRANDA, C.O. A mulher negra e seus desafios na sociedade moderna. In: CONGRESSO NACIONAL DE EDUCAÇÃO, 2, 2015. Anais eletrônicos... Disponível em: <http://www.editorarealize.com.br/ revistas/conedu/trabalhos/TRABALHO_EV045_MD4_SA9_ID5777_07092015110906.pdf>. Acesso em: 24 maio 2018.

MOUTINHO, L. Razão, "cor" e desejo: uma análise comparativa sobre relacionamentos afetivo-sexuais "inter-raciais" no Brasil e na África do Sul. São Paulo: Ed. UNESP, 2004. 
PESTANA, M. Desafios do negro no mundo. Revista Raça (on line), n.190, [s.p.], out. 2016. Disponível em: <https:/ / revistaraca.com.br/desafios-do-negro-no-mundo/>. Acesso em: 27 maio 2018.

RAMOS, L. Na minha pele. Rio de Janeiro: Schwarcz, 2017.

REIS, P.P. A miscigenação e a etnia brasileira. Revista de História, v. 26, n. 48, p. 323-337, 1961.

RIBEIRO, M.; PIOVESAN, F. Dossiê 120 anos da Abolição. Estudos Feministas,v. 16, n. 3, p. 424, set./dez. 2008.

SANTOS, M.A. Contribuição do negro para a cultura brasileira. RTES - Temas em Educação e Saúde, v.12, n.2, p. 217-229, jul./dez. 2016.

SANTOS, R.F.; MARQUES, A.J. Diversidade étnico-racial: conceitos e reflexões na escola. In: ENCONTRO REGIONAL DE HISTÓRIA DA ANPUH, 15, 2012, Rio de Janeiro. Anais Eletrônicos. Disponível em: http:/ / www.encontro2012.rj.anpuh.org/resources/anais/15/1337560631_ARQUIVO_TEXTOANPUH-2012.pdf Acesso em: 26 ago. 209.

SAVOIA, M.G.; CORNICK, M.A.C.P. Psicologia Social. 2.ed. São Paulo: McGraw Hill, 1989.

SILEI, F. O ônibus de Rosa. São Paulo: SM, 2011.

SILVA, C.F. A contribuição da cultura afrodescendente para o samba como parte da identidade musical brasileira. Vozes, Pretérito \& Devir, ano 3, v. 6, n. 1, 2016.

TEIXEIRA, M. Política de branqueamento da população brasileira. WCAR, 2017.

ZAPAROLI, R.A. Conceito de liberdade em Aristóteles e no Existencialismo sartreano. Revista Eletrônica da Faculdade de Direito de Franca, v. 11, n. 1, Jul., 2016.

Data de submissão: 06/ dez./ 2018

Data de aceite: $27 /$ jul./ 2019 